\title{
The influence of hollow billet thickness in rotary compression
}

\author{
Janusz Tomezak $^{1} \cdot$ Zbigniew Pater $^{1} \cdot$ Tomasz Bulzak $^{1}$
}

Received: 15 December 2014 / Accepted: 12 June 2015 / Published online: 2 July 2015

(C) The Author(s) 2015. This article is published with open access at Springerlink.com

\begin{abstract}
The study presents a selection of numerical and experimental results of producing hollow stepped shafts. The first part of this study describes the advantages of using hollow parts in machine design and discusses the main fields of their applications. Next, an innovative rotary compression method for producing stepped axes and shafts is proposed. In order to estimate the technological potential of rotary compression, we performed comprehensive numerical and experimental analyses of producing hollow stepped shafts by this new technique. First, the rotary compression process for hollow parts was modeled numerically by the finite element method. The 3D modeling was made using the Simufact Forming software. The numerical results were then verified by experimental tests conducted under laboratory conditions. The experiments were performed using a machine designed by the authors of the present study. The following variables were investigated in the experiments: the effect of billet wall thickness on the process, the quality and geometry of products, and variations in loads and torques. The experimental results confirm that rotary compression can be used to produce hollow stepped shafts with a wide range of thicknesses.
\end{abstract}

Keywords Rotary compression · Hollow parts · Stepped shafts $\cdot$ FEM $\cdot$ Experiment

Tomasz Bulzak

t.bulzak@pollub.pl

1 Lublin University of Technology, Lublin, Poland

\section{Introduction}

Hollow shafts and axles are nowadays widely used in automotive, aircraft, and machine-building industries [1]. The popularity of hollow parts predominantly stems from the fact that they have high strength properties, comparable to those of solid parts (usually under bending and twisting loads), while their weight is lower. As a result, machines comprising hollow parts are lightweight and thus less energy consuming and more environment friendly (due to reduced fuel consumption and emissions).

Rotary compression is a method which can be used for producing axisymmetric hollow shafts and axles. This method consists in rotational reduction of a hollow billet (tube or sleeve) by three tools (rolls) which rotate and translate toward the workpiece axis (Fig. 1). The tools have the shape of stepped rolls, and their profile corresponds to the shape of the shaft to be formed. Due to the rotary action of the tools, the outside diameter of shaft steps is successively reduced. This is accompanied by an increase in wall thickness of the workpiece, which is desired due to strength and often constructional reasons.

Rotary compression is a new and hence not yet wellinvestigated process for manufacturing hollow stepped shafts. What has been determined so far is the set of variables that can affect this process. The variables which have an influence on the rotary compression process include the ratio of the linear velocity of the rolls to their rotational speed, $v / n$, and the reduction ratio, $\delta$, defined as $\delta=D / d(D$-initial diameter, $d$-diameter after reduction). An increase in the $v / n$ ratio leads to a higher wall thickness and smaller elongation of the product. On increasing the reduction ratio $\delta$, the length and wall thickness of the workpiece increase too [2].

There are several metal forming methods for producing hollow shafts. Hollow parts are usually manufactured by 


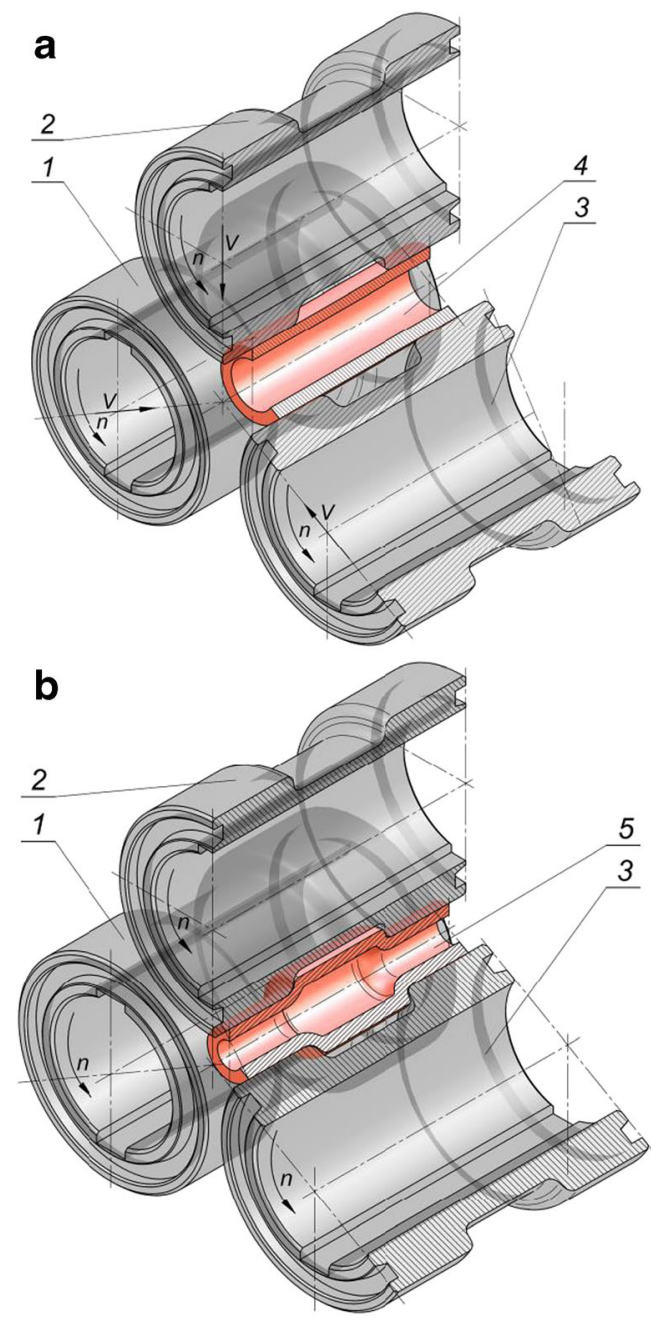

Fig 1 Schematic design of the rotary compression process for a shaft with necked ends: a start of the process, $\mathbf{b}$ end of the process; 1,2 , and 3-forming rolls; 4-hollow billet; and 5-finished part

rotary forging, upsetter forging, extrusion and welding, flow forming, and hydroforming [3-7]. Research is also conducted to investigate if hollow shafts can be produced by cross wedge rolling (CWR) [8]. Recent developments in such innovative forming methods as spin extrusion and rotary compression confirm that the issues of forming hollow stepped shafts are still relevant today $[9,10]$. However, the aforementioned methods for producing hollow shafts require using sophisticated machines or performing more operations [11]. An alternative technique for producing hollow parts is rotary compression. Given that rotary compression is a new technique for manufacturing hollow parts, it is crucial to conduct basic research in order to verify the suitability of this process for metal forming.

Wall thickness of a hollow billet holds crucial importance in processes for manufacturing hollow parts. The results reported by Bartnicki in [12] demonstrate that the smaller the wall thickness of the hollow billet used in CWR, the more likely the risk of uncontrolled slipping and product crushing is. The production of hollow parts by CWR with flat wedges is considerably limited by the potential occurrence of uncontrolled slipping that can cause crushing of the shaft step being formed $[13,14]$. The CWR process for hollow parts runs more smoothly if an internal mandrel is applied [15], which is confirmed by the results of the research conducted by Neugebauer. The stability of the CWR process for hollow parts is also higher when three rolls are applied [16]. The main limitation of CWR by three rolls is the diameter of the rolls, as it cannot exceed the limit value. In effect, this means a shorter length of the roll wedge. Consequently, the spreading angle becomes higher, which not only leads to substantial wall thinning but also poses the risk of workpiece axial failure [17]. Taking the above into consideration, a rotary compression technique free from the failure modes which occur in the conventional CWR was developed $[18,19]$. It must be noted that the previous research on the CWR process for hollow parts mainly focused on producing shafts with simple shapes. However, there are no studies on CWR for multi-stepped hollow shafts. The studies made by Ji et al. demonstrate that the accuracy of the CWR process for hollow shafts depends on values of angles characterizing tool geometry. The research conducted by $\mathrm{Ji}$ et al. also investigated the process for a hollow shaft with a simple shape [20]. The rotary compression technique has been verified in this respect, and the results are reported in [21]. A stepped shaft produced in these experiments is shown in Fig. 2. To describe this process better, it is crucial to determine the significance of initial wall thickness of a billet in rotary compression.

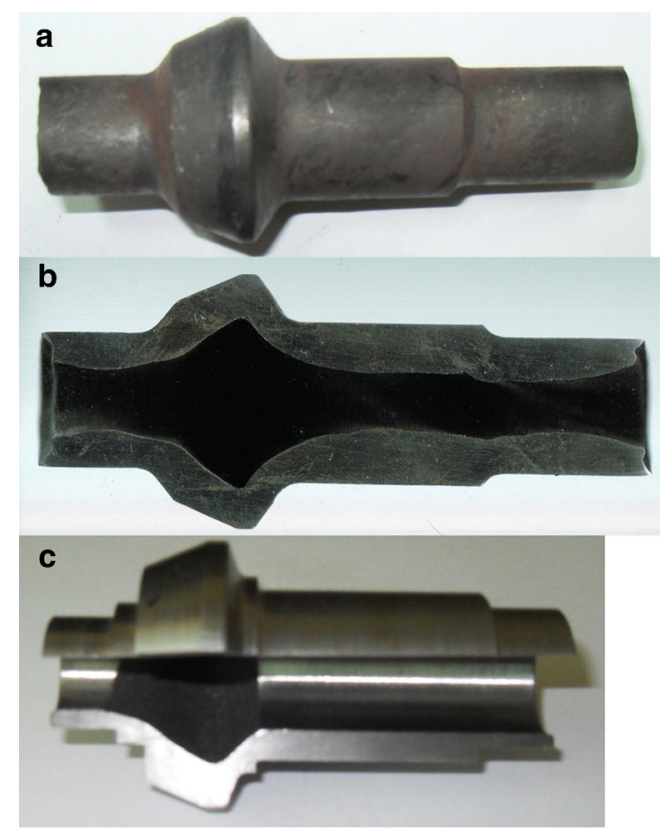

Fig. 2 Example of a part produced by rotary compression: a forging, $\mathbf{b}$ axial section of the forging, and $\mathbf{c}$ finished product after machining 
Hollow parts can be manufactured by upsetter forging from both solid and hollow billets. When hollow billets are used, one can distinguish three types of forming where billet wall thinning occurs: external upsetting, internal upsetting, and external-internal upsetting [22]. What limits the upsetting process for tubes is the maximum wall thickness ratio in one pass defined as $w t r=t_{1} / t_{o}$ (wtr-the wall thickness ratio, $t_{1}$ - the wall thickness after upsetting, $t_{o}$ - the initial wall thickness). The maximum allowable wall thickness ratio $w t r$ is in external upsetting $w t r=1.5$, in internal upsetting $w t r=2$; in externalinternal upsetting $w t r=1.5$ [23].

In the rotary forging process for producing hollow shafts from hollow billets, the thickness of the workpiece wall increases compared to the initial thickness of the billet [1]. The higher the reduction ratio is, the higher the wall thickness of the workpiece becomes. To produce a part with a constant wall thickness, rotary forging is performed with the use of an internal mandrel. The extent of changes in wall thickness in rotary forging also depends on initial wall thickness of the billet. If the billet wall thickness is higher, the growth in wall thickness of the workpiece is smaller in open-die forging [24].

Initial thickness of a workpiece wall is a significant variable in the hydroforming process. A higher initial wall thickness of the hollow workpiece leads to a higher internal pressure, which is responsible for material deformation. What can also occur in the hydroforming process is a phenomenon of local wall thinning which can cause workpiece failure [25]. For this reason, initial wall thickness is an important variable in the hydroforming process. This variable should be set so as to maintain the internal pressure minimal and prevent excessive thinning of the workpiece wall.

Given that there are no data about the impact of wall thickness of a hollow billet in rotary compression, this paper investigates the impact of initial thickness of the billet wall, $t_{o}$, on the realization and stability of the rotary compression process.

\section{Object of the analysis}

Most stepped axes and shafts used in machine design are characterized by a relatively small difference in the diameters of the adjacent steps $(D / d)$ [26]. For the reasons of strength, this parameter is usually set to 1.5 or even lower. Given the above, in the present analysis, the reduction ratio of the end steps of the stepped shafts to be produced was defined as $\delta=D /$ $d$ and set to 1.5 . In addition, it was assumed that the steps would be formed by hot rotary from semifinished products - sections of commercial tubes with a different initial wall thickness, $t_{o}$, that was $4,5,7,9$, and $11 \mathrm{~mm}$, respectively. The shape and dimensions of the billet and shafts to be produced are shown in Fig. 3.

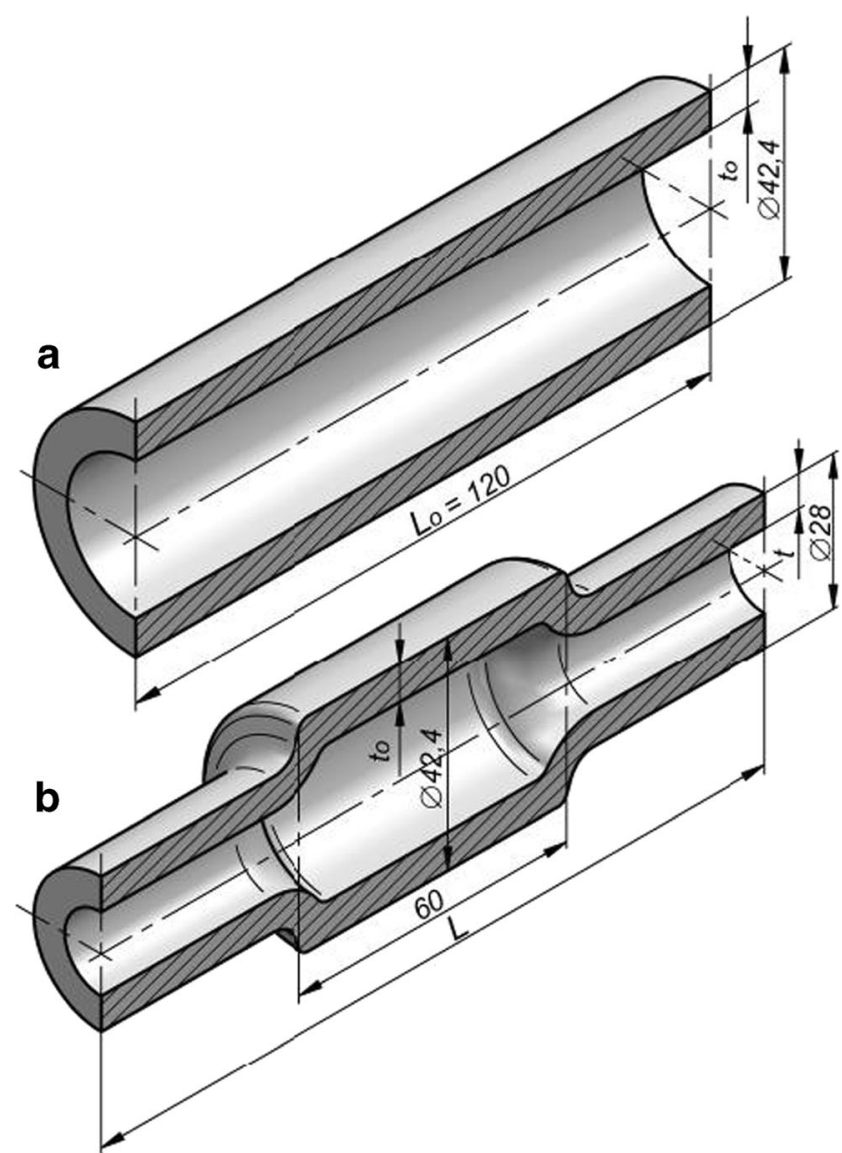

Fig. 3 Shape and dimensions of a hollow billet and $\mathbf{b}$ hollow shaft produced by rotary compression

\section{Numerical modeling of rotary compression}

First, the rotary compression process for hollow shafts was modeled numerically. The modeling was made by the finite element method (FEM) using the simulation software Simufact Forming v. 12.0, which had previously been used by the present authors to investigate rotary metal forming processes. One of the geometrical models created for the purposes of the investigation is shown in Fig. 4. The model comprises three identical tools (shaping rolls) and a workpiece (C45 steel tube with the outside diameter $D=42.4 \mathrm{~mm}$, wall thickness $t_{o}$, and length $L=120 \mathrm{~mm}$ ) that was modeled by eight-node elements of the first order. As already mentioned, the simulations were performed using tubes that had different initial wall thicknesses, $t_{o}$; they were: $4,5,7,9$, and $11 \mathrm{~mm}$, respectively. The rigidplastic material model of $\mathrm{C} 45$ steel was obtained from the material database library of the simulation software applied [27]. It is defined as follows:

$\sigma_{p}=2859.85 \cdot e^{(-0.00312548 T)} \cdot \varepsilon^{(0.000044662 T-0.101268)}$ 


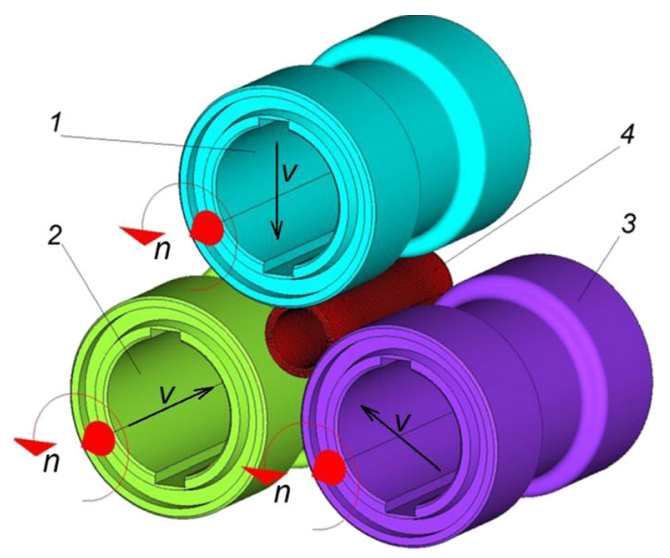

Fig. 4 Geometrical model of rotary compression for hollow shafts: 1, 2, and 3-tools; 4-workpiece

where

$T$ is the temperature (from 700 to $1250{ }^{\circ} \mathrm{C}$ )

$\varepsilon \quad$ is the strain

$\dot{\varepsilon} \quad$ is the strain rate

Prior to forming, the workpiece was heated over its whole volume to a temperature of $1150{ }^{\circ} \mathrm{C}$. During the forming process the temperature of the tools was maintained constant at $100{ }^{\circ} \mathrm{C}$. The rolls were rotated in the same direction with the same velocity, $n$, set to $36 \mathrm{rpm}$. At the same time, they were moving to the axis of the workpiece with the constant velocity $v$ fixed at $3.0 \mathrm{~mm} / \mathrm{s}$. The material-tool contact surface was described by the constant friction model with the boundary value of the friction factor $m$ set to 1 [28]. The heat transfer coefficient between the material and the tools was $25 \mathrm{~kW} /$ $\mathrm{m}^{2} \mathrm{~K}$, while the material-environment heat transfer coefficient was set to $0.35 \mathrm{~kW} / \mathrm{m}^{2} \mathrm{~K}$.

As mentioned above, in rotary compression, the tools are rotated in the same direction. At the same time, however, they move to the axis of the workpiece, which leads to the forming of the end steps of the shaft. After putting the tools in the required position corresponding to the required reduction ratio $\delta=1.5$, which corresponded to the diameter of the steps being formed $(d=29 \mathrm{~mm})$, the translational motion of the rolls was stopped. As predicted, the reduction in the outside diameter of the workpiece was accompanied by the material's rapid radial flow (to the axis of the workpiece), which resulted in increasing the thickness of the workpiece in the tool-action regions (Fig. 5). In addition, the metal underwent axial displacement in these regions, which increased the workpiece length. An analysis of the FEM-predicted effective strain distribution (Fig. 5) reveals a significant lack of homogeneity of the results. It is also to be observed that the initial wall thickness has a profound effect on the magnitude of strains and their distribution pattern. Despite the fact that the reduction ratio was set the same in all investigated cases, we can observe that the strains and the discrepancies with regard to their distribution
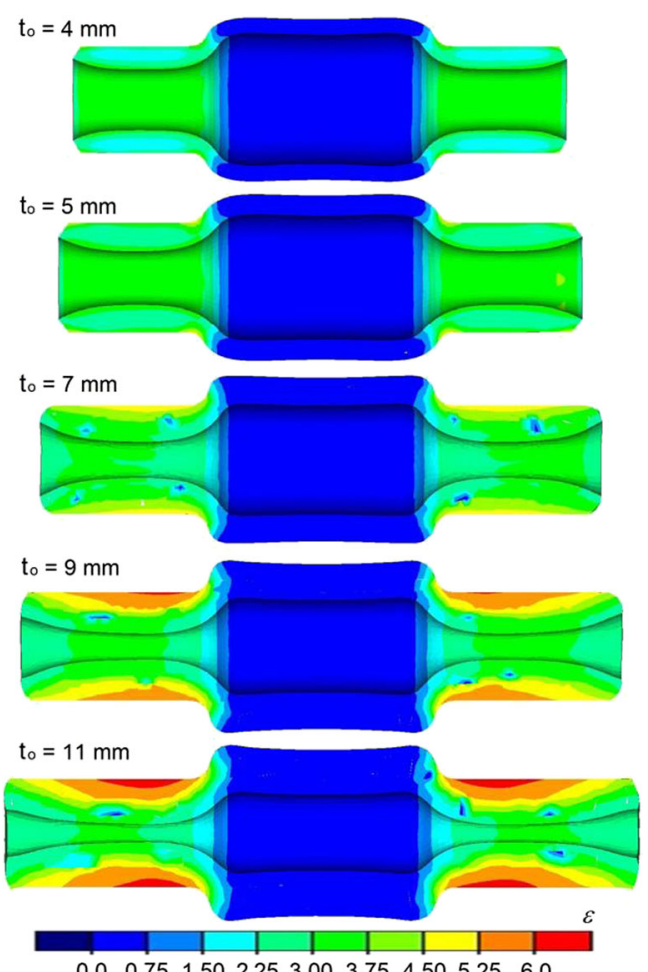

$\begin{array}{lllllllll}0,0 & 0,75 & 1,50 & 2,25 & 3,00 & 3,75 & 4,50 & 5,25 & 6,0\end{array}$

Fig. 5 FEM-predicted effective strain distribution in shafts with different initial wall thicknesses

increase with increasing the thickness of the initial wall of the workpiece. More specifically, increasing the wall thickness from 4 to $11 \mathrm{~mm}$ leads to an over threefold increase in the effective strain at the same outside diameter reduction ratio. This is undoubtedly caused by the fact that a higher volume of the material is displaced in both radial and axial directions.

The performed numerical analysis demonstrates that the strains in rotary compression significantly differ with regard to their distribution in both cross and longitudinal sections of the shaft steps being formed. In all investigated cases, the distribution pattern of effective strains in these regions is ring-shaped (Fig. 6). The material is most deformed in the layers that are close to the surface. However, the closer it is to the surface of the hole, the smaller the strains become. Typical of most rotational forming processes, this phenomenon is caused by the additional, circumferential strains produced on the material-tool contact surface by the friction forces. It must, however, be stressed that these strains do not alter the product geometry; they only increase the magnitudes of product geometry parameters. Also, it can be observed that the increase in the workpiece wall thickness leads to higher redundant strains in the region of the steps being formed. This can be attributed to higher deformation resistance values to the metal's radial flow that occur when forming shafts with thicker walls. This creates favorable conditions for increased slipping on the metal-tool contact surface and, consequently, the occurrence of additional strains. 
Fig. 6 FEM-predicted effective strain distribution in cross sections of shaft steps produced from tubes with different initial wall thicknesses

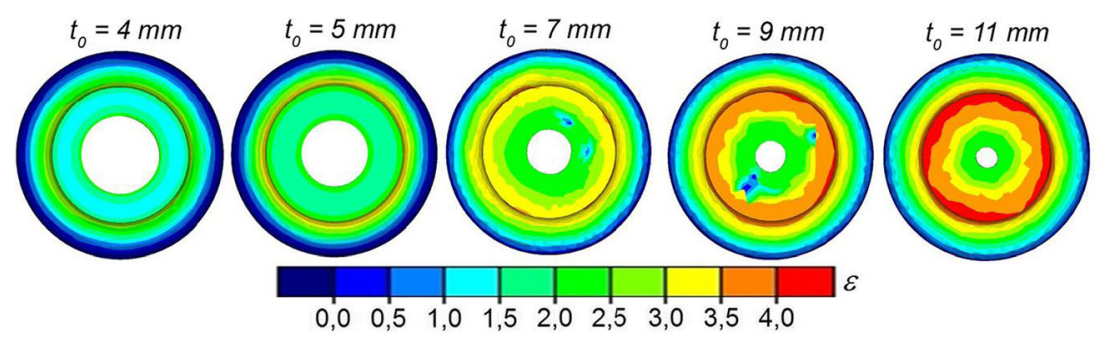

When solid axisymmetric parts are produced by rotary compression, this can lead to internal cracking of the material, which mainly results from low-cycle fatigue [29]. In rotary compression for hollow parts, there is also a risk of material cracking owing to the cyclic variability of stresses during the reduction of the workpiece diameter. The risk of material cracking in the forming of hollow parts was estimated by means of the normalized Cockroft-Latham failure criterion expressed as follows [30]:

$C=\int_{0}^{\varphi} \frac{\sigma_{1}}{\sigma_{i}} d \varphi$,

Fig. 7. As expected, the produced steps, especially those of the shafts with small wall thicknesses, have a tendency for considerable cooling and the temperature drops can be observed practically in their entire section. The temperature of such products drops even to approx. $700{ }^{\circ} \mathrm{C}$ in the region of the steps being formed. When parts with thicker walls are formed, the temperatures have somewhat different distribution patterns. Here, the temperature drops occur locally, on the surface of parts. In these cases, the further it is from the surface layers that are in direct contact with the tools, the higher the temperature of the material is. Owing to such distribution pattern, heat losses in the surface layers can be compensated for and the temperature of the step being formed can be maintained high (at a level suitable for hot metal forming) for a relatively long time. It is worth noting that for all investigated thickness variants, the central steps of the shafts which do not undergo deformation retain their high temperatures which are slightly lower than the initial temperature to which the workpiece was heated. Obviously, the main reason for the temperature drops in the region of the steps is the fact that the workpiece is in contact with the much colder tools. It is, however, to be noted that despite a relatively long forming time (about $8 \mathrm{~s}$ ), the temperature does not drop below $700{ }^{\circ} \mathrm{C}$, which can be explained by the fact that heat losses are compensated for by the deformation and friction that generate substantial amounts of heat. In this context, it should be emphasized that the rotary compression process for hollow parts with small wall thicknesses would be much more difficult to run due to excessive cooling of the material practically in the entire section of the step being formed. In effect, this will lead to lower plastic deformability of the material and, at the same time, to higher deformation resistance. This phenomenon often leads to cross-sectional defects, such as excessive ovalization of the steps.

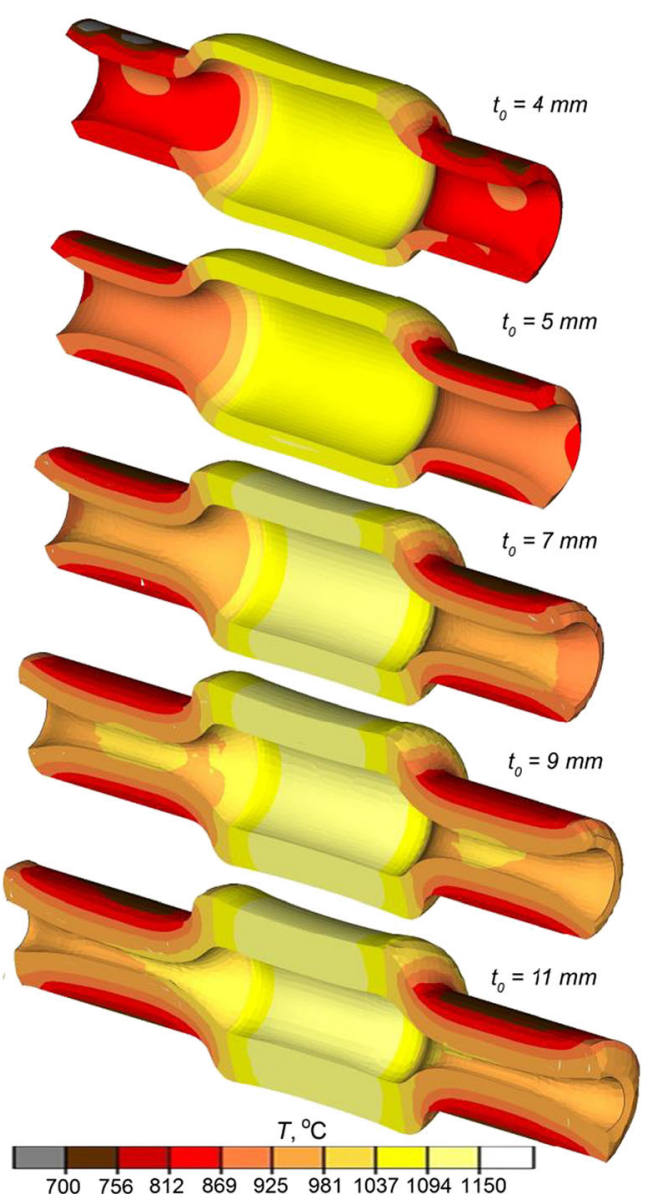

Fig. 7 FEM-predicted temperature distribution in the final stage of rotary compression for producing hollow stepped shafts with different initial wall thicknesses 
where

$\sigma_{1} \quad$ is the maximum principal stress

$\sigma_{i} \quad$ is the effective stress

$\varphi \quad$ is the strain

$C$ is the Cockroft-Latham failure criterion

Determined with Eq. (2), the Cockroft-Latham criterion is compared with the experimental limit value.

The results (Fig. 8) demonstrate that these are the surface layers of the hole (in the regions of the steps being formed) that are most prone to cracking in the rotary compression process for hollow parts. The Cockroft-Latham criterion attains the maximum values in these regions. At the same time, it was found that the crack occurrence greatly depends on the initial thickness of the workpiece. It was found that the increase in thickness leads to higher values of the damage criterion. This can particularly be observed when producing parts made of billets with thicker walls $(t>7 \mathrm{~mm})$, where the Cockroft-Latham criterion attains the maximum values (about 1.2) that exceed the limit values for typical constructional steel leading to cracking of the material [28]. It can, however, be observed that the range of the criterion's maximum values is

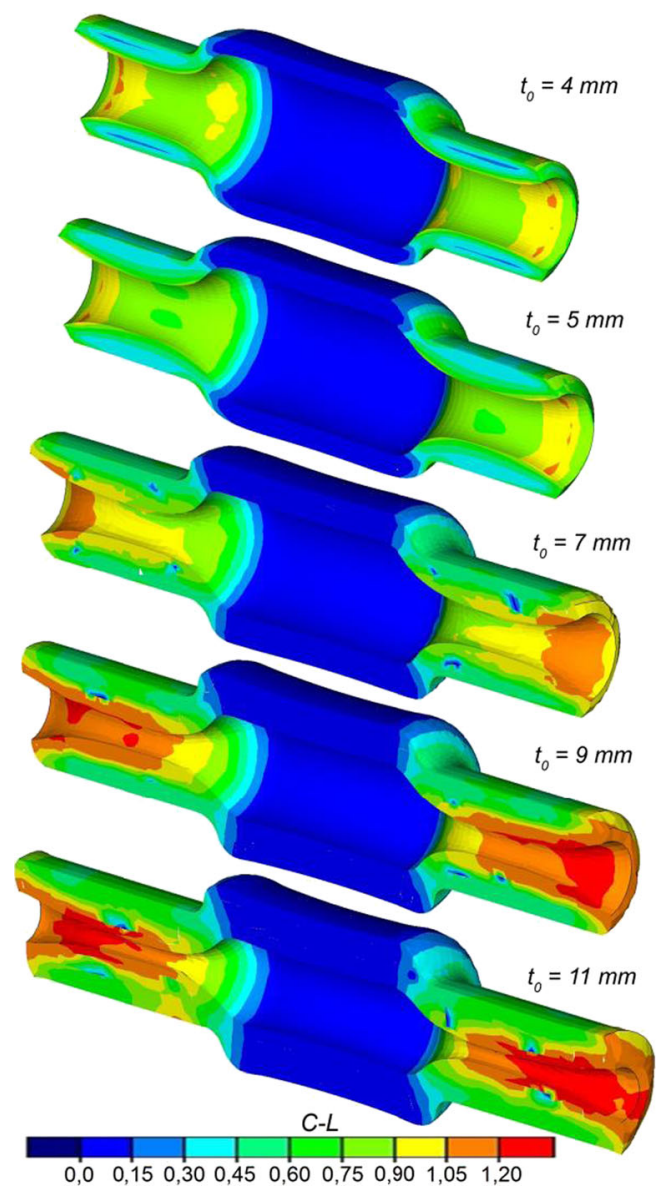

Fig. 8 FEM-predicted Cockroft-Latham failure criterion distribution in the final stage of rotary compression for hollow stepped shafts with different initial wall thicknesses narrow. These values are mainly concentrated in the nearsurface layers that often form the technological allowance to be removed in finishing.

\section{Experimental tests of rotary compression for hollow stepped shafts}

The numerical results were verified in experimental tests performed under laboratory conditions. The experiments were conducted using a forging machine that had been designed and constructed at the Department of Computer Modeling and Metal Forming Processes at the Lublin University of Technology (Fig. 9). With this machine, the experimental tests of the rotary compression process could be run in compliance with the scheme followed in the numerical simulations. Made up of modules, the machine for rotary compression consists of a frame - 1 , a power unit -2 , a gear box - 3 , a system of rolls 4 , a hydraulic power system of the rolls -5 , a control and power system -6 , and a set of measuring instruments -7 .

The rotary compression was performed by the system of the rolls, consisting of three radially moving slides and three working rolls mounted on the said slides. The translational motion of the slides was synchronized, so that the displacement of the tools was identical during the forming process. The forces and kinematic parameters in the rotary compression process were measured using the measuring system consisting of a torque converter, a displacement sensor, and

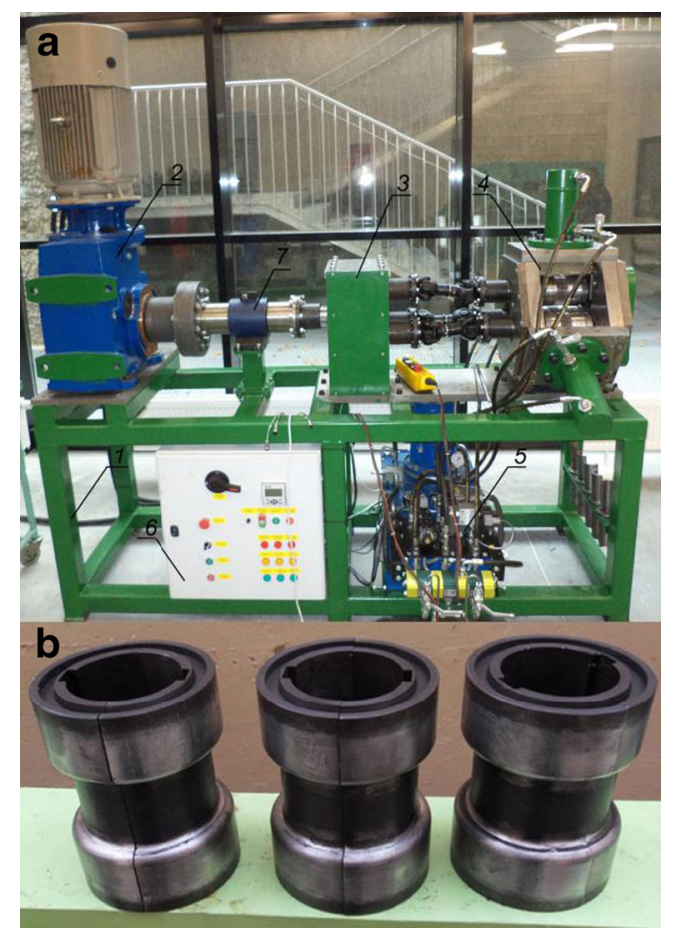

Fig. 9 Machine for rotary compression used in the experiment: a view of the machine and $\mathbf{b}$ set of tools for forming the end steps of a shaft (description in the text) 
pressure measuring sensors. Signals emitted by the sensors were recorded digitally using a portable computer and a measuring card.

The experiments were performed on C45 steel commercial tubes that had the same dimensions as in the FEM modeling. Each tube was first heated in an electric chamber furnace to a forming temperature of approx. $1150{ }^{\circ} \mathrm{C}$ and then fed with the pliers into the machine's working space. Next, the workpiece was set in motion by the rolls which moved radially (relative to the axis of the workpiece) at the constant velocity $v=3 \mathrm{~mm} /$ $\mathrm{s}$ and were rotated in the same direction at the velocity $n=$ $36 \mathrm{rpm}$. As a result, the diameters of two end steps of the shaft were reduced. Once the slides travelled the length corresponding to the required diameter reduction $(\delta=D / d=1.5)$, the translational motion was automatically stopped and the sizing of the workpiece shape was undertaken during further revolution of the rolls. In the final stage of the process, the tools opened in a radial manner (Fig. 10a), and the produced part (Fig. 10b) was ejected from the machine in a special feed device.

The parts produced in the experiments were subjected to free cooling in ambient air. Following their cleaning, the produced parts were inspected and measured.

The primary objective of the experimental tests was twofold: first, to confirm whether rotary compression was a viable method for forming hollow stepped shafts and, second, to verify the FEM numerical models. The technological assumptions were verified based on the estimation of the geometry of produced parts, process stability, and force parameters. The experimental results unanimously confirm that hollow stepped shafts can be produced from tubular billet by the

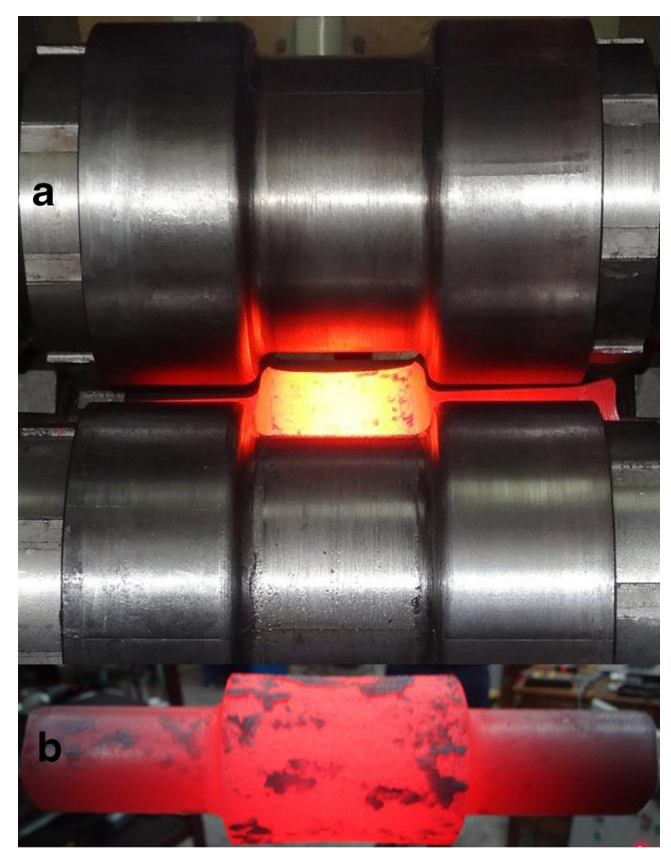

Fig. 10 Experimental tests of producing a hollow shaft: a final stage of the process and $\mathbf{b}$ finished product rotary compression technique. The shafts produced in the experimental tests are shown in Fig. 11.

The experimental results (with regard to the shape and dimensions of parts) show a good agreement with both theoretical assumptions (regarding the designed shape of parts) and the numerical results. Both the experimental and numerical results of rotary compression for hollow parts demonstrate that workpiece thickness increases due to axial flow of the material in the tool-action zone. It can also be observed that the length of all parts increases compared to the initial length of the billet, which results from the axial displacement of the material that occurs in the region of the end steps. Nonetheless, it should be stressed that the high agreement between the experimental and numerical results regarding the geometry of produced parts unanimously confirms that the theoretical assumptions and the designed FEM models were correct.

As already mentioned, the reduction of the outside diameter of the end steps of the shaft leads to higher thickness owing to the material's radial flow. The length of the workpiece increases too due to axial flow of the material in the region of the reduced steps. Interestingly, the rates of increase in the workpiece thickness and length are closely related with the initial thickness of the billets applied. As can be seen in Fig. 12, the thicker the initial thickness of the workpiece is, the lower the rate of increase in thickness and the higher the rate of increase in length. The results of the experiments for the largest thickness billet reveal that the wall of the workpiece becomes thinner compared to its initial value.

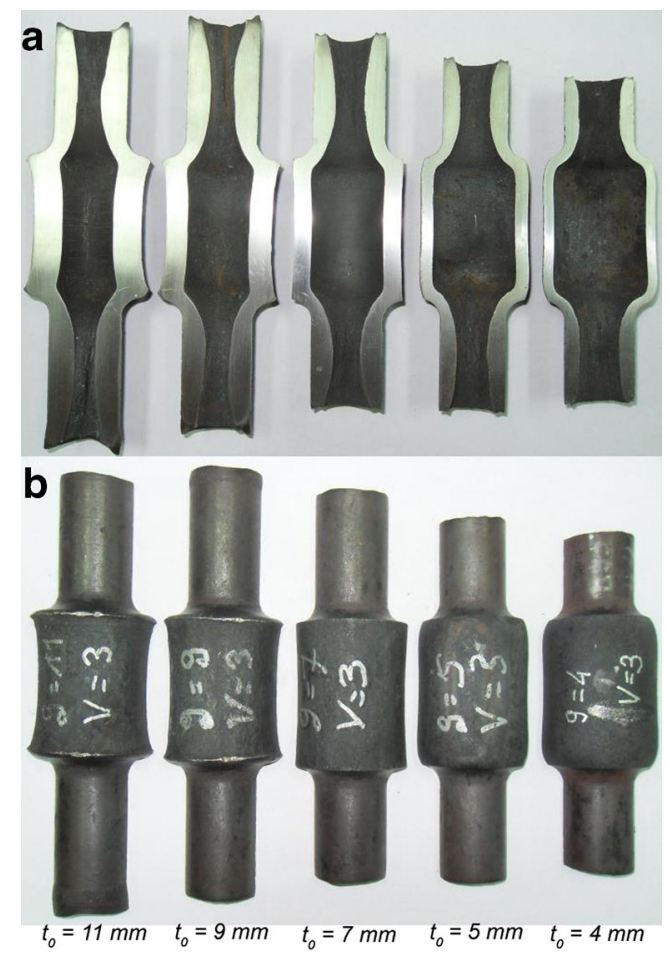

Fig. 11 Shafts produced by rotary compression in the experimental tests: $\mathbf{a}$ axial section and $\mathbf{b}$ general view 


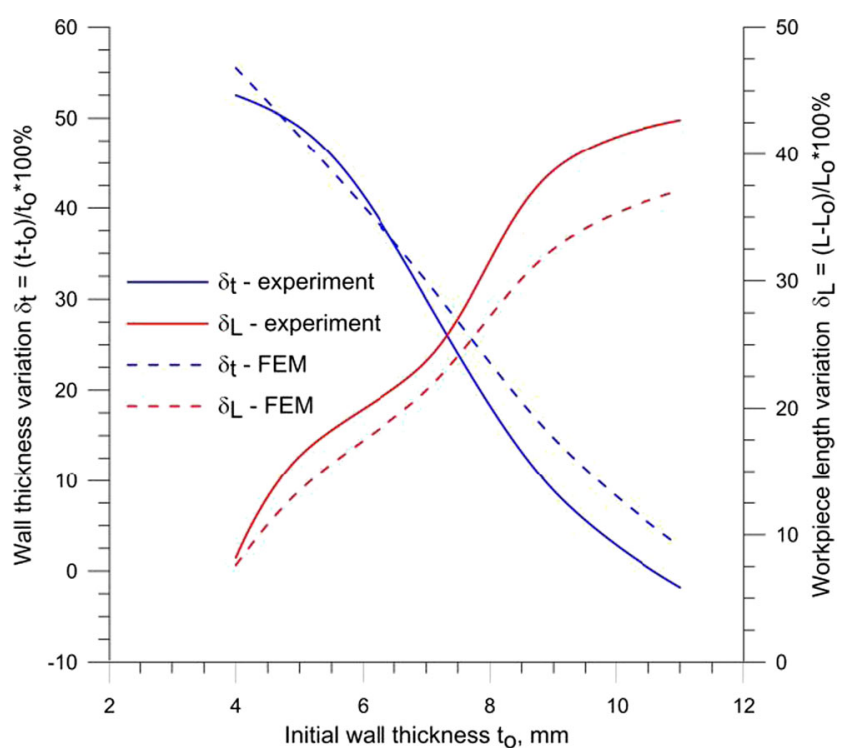

Fig. 12 FEM-predicted and experimental results of workpiece thickness and length

A comparison of the numerical and experimental results reveals that there the produced shafts differ in terms of their dimensions. When the shafts are produced from tubes with thicker walls, the experimental results reveal a much smaller increase in thickness and a much higher increase in length compared to the numerical results. These differences probably result from the fact that it was difficult to maintain thermal conditions identical in the experiments and numerical modeling. Presumably, the high temperature drop that occurred in the experiments caused higher deformation resistance to flow, which - in turn - hindered the radial flow of the material, hence increasing the elongation of the end steps of the shaft. The kinematics of material flow is also greatly affected by the friction forces on the workpiece-tool contact surface. In the FEM modeling, the limit value of the friction factor $m$ was set to 1 [28]. In the experiments, however, the friction factor can be set to a lower value, so the friction forces will be lower too, which will facilitate the axial flow of the material in the surface layers of the steps.

The results of the majority of investigated cases demonstrate considerable variations in wall thickness of the formed steps. What is more, the variations exhibit similar distribution patterns. Figure 13 shows the wall thickness distribution in the shafts produced from tubes with the initial wall thickness $t_{o}=$ $7 \mathrm{~mm}$. The wall is thickest in the central regions of the formed steps. Then, the closer it is to the frontal surfaces and the central step of the shaft (one that is not reduced), the wall thickness gradually decreases. This is caused by the impact of the friction forces on the surface layers of the workpiece during axial flow of material in these regions. Based on the data given in this figure, we can also identify regions where the wall thickness becomes smaller. Predominantly, these regions are located in the vicinity of the surfaces perpendicular

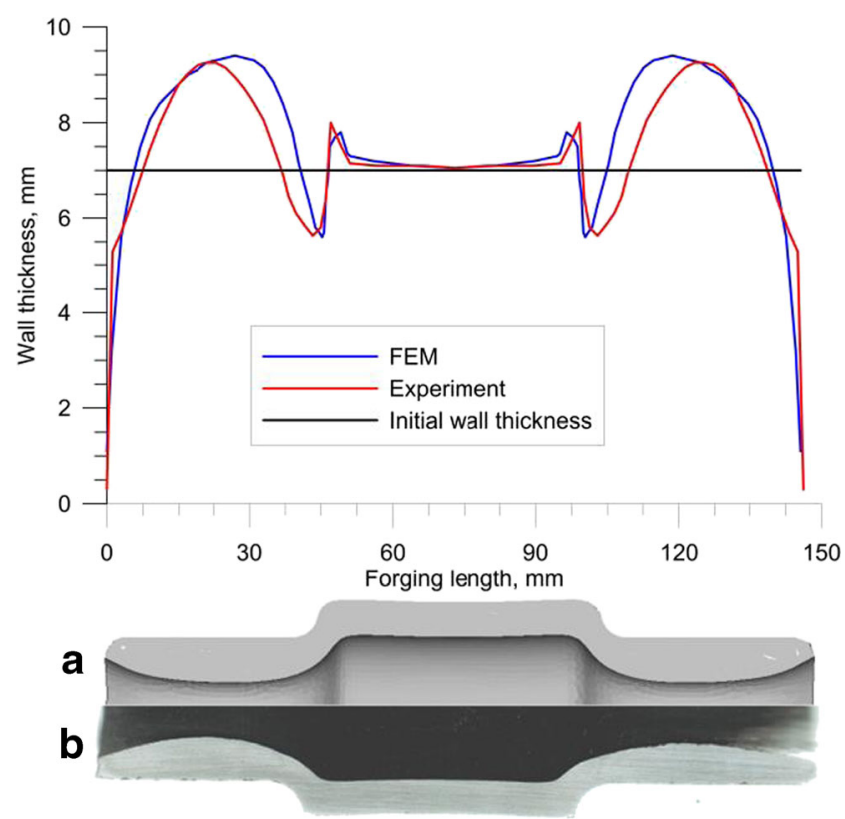

Fig. 13 Wall thickness distribution in a hollow stepped shaft shaped from a tube with the initial thickness $t_{o}=7 \mathrm{~mm}$ : a experiment and b FEM

to the steps, and they are formed when the metal flows on the surface of the workpiece. A considerable thinning of the workpiece wall can also be observed in the regions between the steps and the part of the shaft that does not undergo deformation. This phenomenon can have a negative effect on the strength properties of machine components that comprise such shafts. The wall thinning phenomenon can be explained by the fact that the kinematics of material flow varies in the regions between the steps. Here, apart from material reduction due to action of the tools, the workpiece also undergoes elongation, which leads to a decrease in thickness of the workpiece wall. The corner radii of the tools have a significant effect on the magnitude of wall thinning in these regions. It was observed that the higher these radii are, the lower the rate of decrease in the wall thickness of the workpiece. Consequently, it is recommended that the highest possible radii be applied between the steps of the shaft in order to minimize the negative effects of material elongation. The wall thickness distribution pattern illustrated in Fig. 13 is characteristic of the shafts produced from tubes whose relative wall thickness $(t / D)$ is lower than 0.25 . However, in the rotary compression of hollow parts with thicker walls $(t / D>0.25)$, the resistance values to radial flow are so high that the metal flows mainly over the surface in the axial direction, which considerably increases length of the end steps of the shaft. This leads to the thinning of the workpiece wall (compared to its initial thickness) practically in the entire region of the steps, with a slight increase in thickness of the wall near the surfaces that are perpendicular to the undeformed (central) step (Fig. 14).

The application of the rotary compression method in industrial conditions greatly depends on the magnitude of forming 

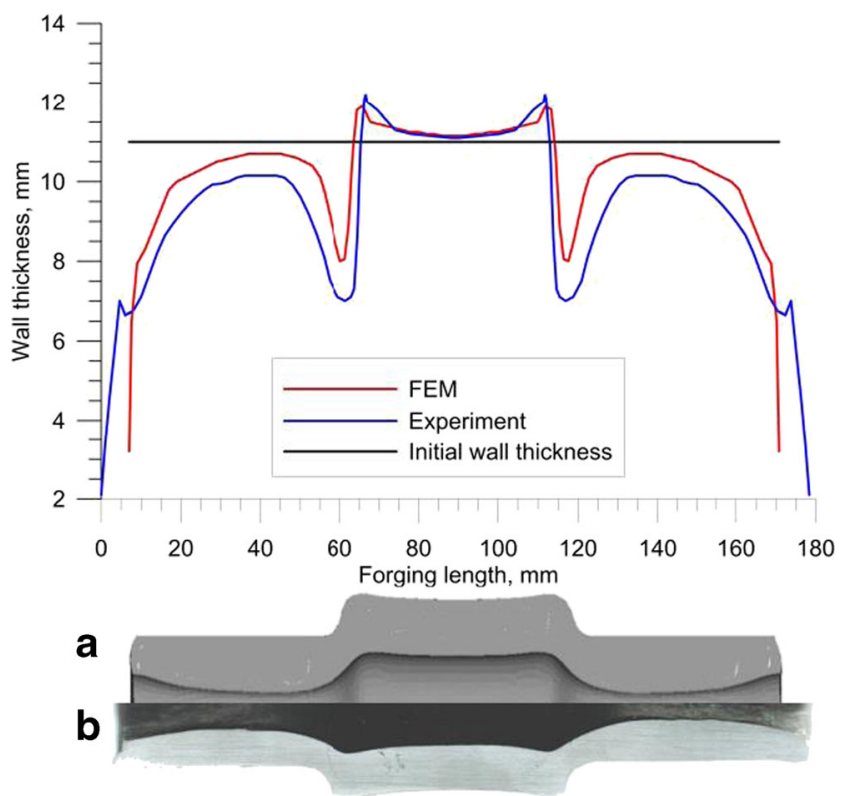

Fig. 14 Wall thickness distribution in a hollow stepped shaft shaped from a tube with the initial thickness $t_{o}=11 \mathrm{~mm}$ : a experiment and $\mathbf{b}$ FEM
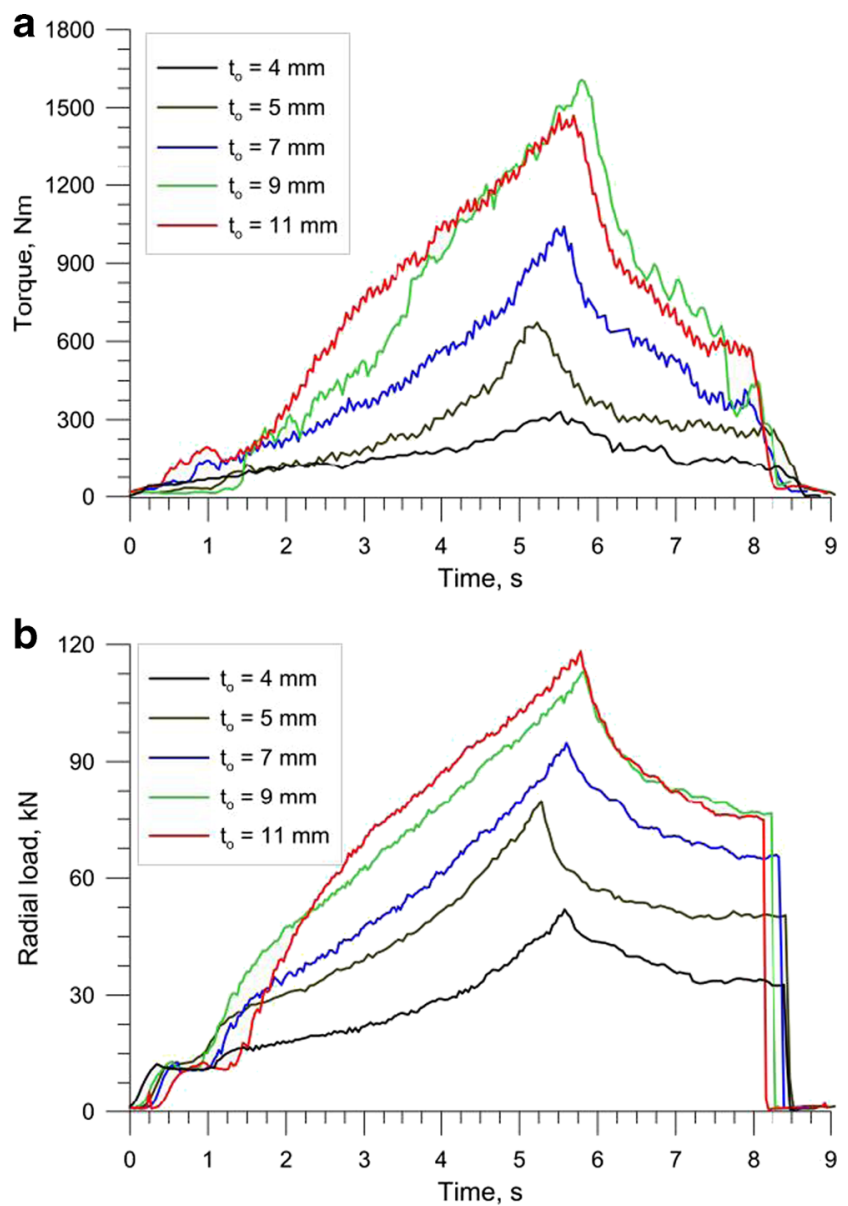

Fig. 15 Experimental results of the force parameters in rotary compression for hollow stepped shafts: a torques and $\mathbf{b}$ radial loads forces. Very often, the research on innovative forming processes is given up very early due to insufficient strength, rigidity, or durability of tools, which - in turn - results from excessive loads or inadequate tool design. The size and power of machines used in forming processes also depend on the magnitude and type of forces that reflect deformation resistance to material flow. For this reason, the present experiments involved estimating the effect of loads and torques on the rotary compression process. We also examined the effect of wall thickness in the shafts being produced on the variations in loads and torques. Based on the results of radial loads and torques given in Figs. 15 and 16, it can be claimed that the new rotary compression technique can be applied in industrial conditions. The maximum values of radial loads and torques do not exceed the capacity of the machine used in the experiments. Obviously, higher thickness of the workpiece wall leads to higher radial loads and torques. In all cases, however, the increase in loads and torques follows a similar pattern. As can be seen in Figs. 15 and 16, the loads and torques rapidly increase at the onset of the forming process, which is caused by the sinking of the tools into the material and gradual reduction of the outside diameter of the end steps. The increase in
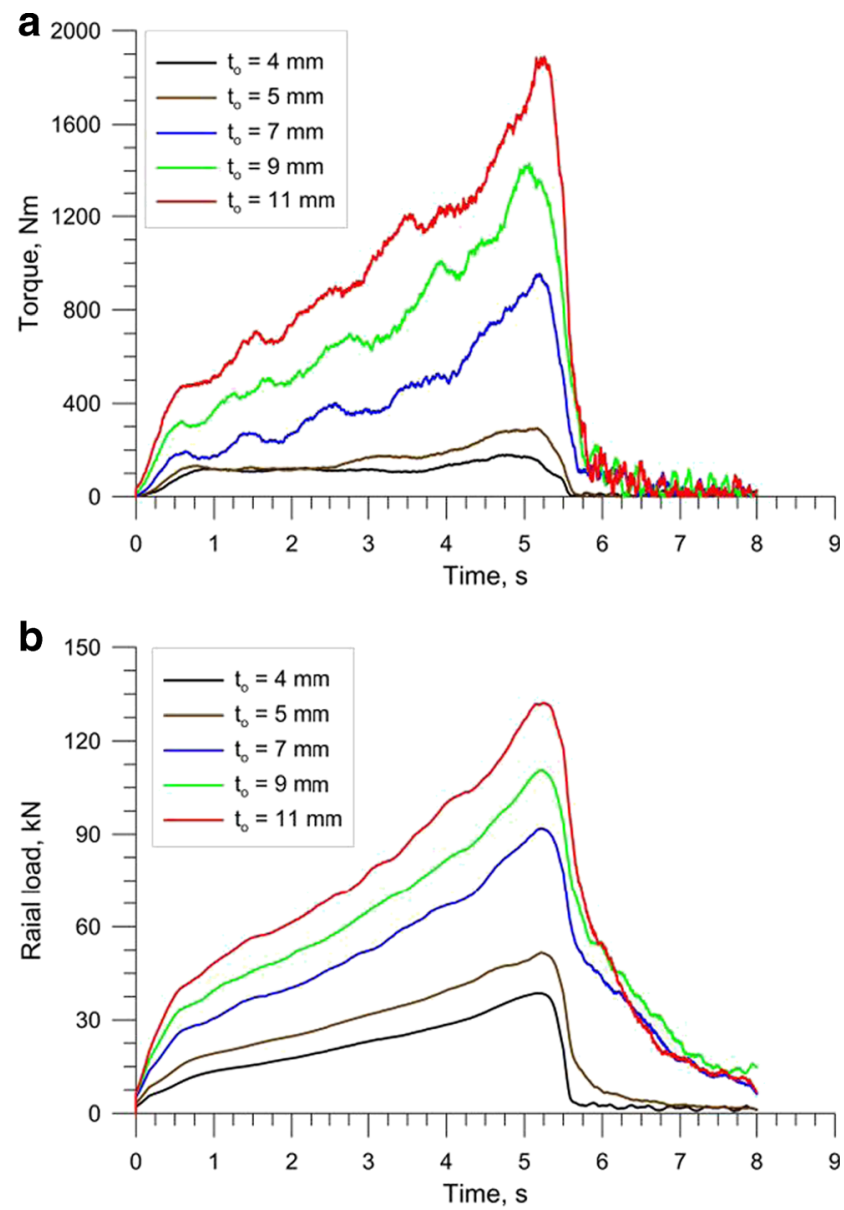

Fig. 16 FEM-predicted variations in the force parameters in rotary compression for hollow stepped shafts: a torques and $\mathbf{b}$ loads 
the loads and torques also results from the drop in the material's temperature and higher relative thickness of the workpiece wall $(t / D)$ in the region of the reduced steps. In all investigated cases, the loads and torques are highest when the position of the tools corresponds to the required reduction in the outside diameter. After that, we can observe a relatively rapid drop in the loads and torques. This marks the final stage of the process, i.e., sizing, when the rolls are only rotated to remove shape inaccuracies of the formed steps. A comparison of the FEM and experimental variations in the loads and torques reveals that they differ, both in terms of their maximum values and distribution patterns.

It can be observed that in the forming of parts with smaller wall thicknesses $(t / D<0.16)$, the experimental loads and torques are higher than those predicted by FEM. The observed differences probably result from the discrepancies between the real thermal conditions and the theoretical ones. When forming parts with smaller wall thicknesses, the material cools faster compared to the numerical model, which makes the loads and torques increase. This observation is confirmed by much less significant differences in the loads and torques that were observed for parts with thicker walls. The thermal capacity of such parts is higher, so their temperature remains relatively high too, which ensures better plastic deformability of the material.

Interestingly, at the beginning of the rotary compression process, the FEM-predicted and experimental distributions of force parameters are similar. A sharp difference can only be observed in the final stage of forming, i.e., sizing. Here, the experimental loads and torques decrease much more slowly compared to the FEM results. This results from the fact that the workpiece surface layers cool here more rapidly than predicted by the numerical model. In effect, the shape defects (mainly cross-sectional ovalization of the formed steps) are removed at higher material flow resistance, which affects the radial loads and torques.

\section{Summary and conclusions}

The numerical and experimental results reveal the significance of the initial thickness of billet wall, $t_{o}$, in the rotary compression process. Based on these findings, the following conclusions have been made:

- With higher initial thickness of the workpiece wall, the elongation of the steps increases, while the wall thickness growth decreases.

- The forming of thin-walled parts is characterized by a rapid flow of metal in the radial direction. In the forming of thick-walled parts by rotary compression, the material flows on the workpiece surface in the axial direction.
- The increase in wall thickness of the workpiece leads to higher redundant strains in the surface layers of the formed steps.

- The new forming method for hollow parts can cause the superficial cracking of the hole wall. The risk of material cohesion loss is much higher with thick-walled billets.

- It is recommended that the largest possible corner radii be applied between the steps of the shafts.

- Higher wall thickness of the workpiece leads to higher radial loads and torques.

- It is recommended that further research be performed to examine the relationships between the process variables and the quality and properties of produced parts.

- It is justified that further research on rotary compression be conducted to investigate its application to the production of hollow parts with teeth and worms.

Summing up, hollow stepped shafts can be manufactured by the rotary compression technique. It should be stressed that the results demonstrate that stepped shafts can be produced by rotary compression from hollow billets in a wide range of wall thicknesses.

Open Access This article is distributed under the terms of the Creative Commons Attribution 4.0 International License (http://creativecommons.org/ licenses/by/4.0/), which permits unrestricted use, distribution, and reproduction in any medium, provided you give appropriate credit to the original author(s) and the source, provide a link to the Creative Commons license, and indicate if changes were made.

\section{References}

1. Piwek V, Kuhfuss B, Moumi E, Hork M (2010) Light weight design of rotary swaged components and optimization of the swaging process. Int J Mater Form 3:845-848

2. Tomczak J, Pater Z, Bulzak T (2013) Effect of technological parameters on the rotary compression process. Eksploatacja $i$ Niezawodnosc - Maint Reliability 15:279-283

3. Kettner P, Schmieder F (1997) Manufacturing of hollow transmission shaft via bulk - metal forging. J Mater Process Technol 71: $113-118$

4. Lim S-J, Choi H-J, Lee C-H (2009) Forming characteristics of tubular product through the rotary swaging process. J Mater Process Technol 209:283-288

5. Groche P, Fritsche D (2006) Application and modelling of flow forming manufacturing processes for internally geared wheels. Int J Mach Tools Manuf 46:1261-1265

6. Zhang Q, Wu C, Zhao S (2012) Less loading tube-hydroforming technology on eccentric shaft part by using movable die. Mater Trans 53:820-825

7. Yamanaka S, Kazama T, Dohi M (2005) Hollow stepped shaft and method of forming the same. United States Patents No. US 2005/0016246

8. Urankar S, Lovell M, Morrow C, Kawada K (2006) Establishment of failure conditions for the cross-wedge rolling of hollow shafts. J Mater Process Technol 177:545-549 
9. Neugebauer R, Kolbe M, Glass R (2001) New warm forming processes to produce hollow shaft. J Mater Process Technol 119:277282

10. Tomczak J, Pater Z, Bulzak T (2015) Forming of hollow shaft forging from titanium alloy Ti6Al4V by means of rotary compression. Arch Metall Mater 60:419-425

11. Qin Y, Ma Y, Balendra R (2004) Pressurising materials and process design considerations of the pressure-assisted injection forging of thick-walled tubular components. J Mater Process Technol 150:3039

12. Bartnicki J, Pater Z (2005) The cross-wedge rolling process of hollowed parts. Lublin University of Technology Press, Lublin

13. Pater Z, Bartnicki J (2006) Wedge-rolls rolling of hollowed parts. J Achiev Mater Manuf Eng 18:407-410

14. Urankar S, Lovell M, Morrow C, Li Q, Kawada K (2006) Development of a critical friction model for cross wedge rolling hollow shafts. J Mater Process Technol 177:539-544

15. Neugebauer R, Glass R, Kolbe M, Hoffmann M (2002) Optimisation of processing routes for cross rolling and spin extrusion. J Mater Process Technol 125-126:856-862

16. Bartnicki J, Tomczak J, Pater Z (2015) Numerical analysis of the cross-wedge rolling process by means of three tools of stepped shafts from aluminum alloy 7075. Arch Metall Mater 60:433-435

17. Bartnicki J, Pater Z (2005) Numerical simulation of three-rolls cross wedge rolling of hollowed shaft. J Mater Process Technol 164-165: 1154-1159

18. Pater Z, Tomczak J (2013) Method for plastic forming of toothed shafts. European patent no. EP 2422898
19. Pater Z, Tomczak J (2013) Rotary compression of hollow parts by cross rolling. European patent no. EP 2422896

20. Ji H, Liu J, Wang B et al (2015) Cross-wedge rolling of a 4Cr9Si2 hollow valve: explorative experiment and finite element method simulation. Int J Adv Manuf Technol 77:15-26

21. Pater Z, Gontarz A, Tomczak J, Bulzak T (2015) Producing hollow drive shafts by rotary compression. Arch Civil Mech Eng. doi: 10.1016/j.acme.2014.10.002

22. Tang H, Hao C, Jiang Y et al (2010) Forming process and numerical simulation of making upset on oil drill pipe. Acta Metall Sin 23:7280

23. Semiatin, S.L. (ed) (1990) ASM Handbooks. Metalworking: bulk forming, Volume 14A. ASM International, USA

24. Lipski T (1979) Rotary swaging. WNT, Warsaw

25. Orban $\mathrm{H}, \mathrm{Hu} \mathrm{SJ}$ (2007) Analytical modeling of wall thinning during corner filling in structural tube hydroforming. J Mater Process Technol 194:7-14

26. Dabrowski Z, Maksymiuk M (1984) Shafts and axles. Polish Scientific Publishers, Warsaw

27. Simufact Engineering (2012) Simufact.material 2012. 0.0.14871. Simufact engineering gmbh, Hamburg

28. Pater Z, Gontarz A, Weroński W (2001) Selected problems of the theory and technology of cross-wedge rolling. Polish Scientific Society, Lublin

29. Pater Z, Tofil A (2007) Experimental and theoretical analysis of the cross-wedge rolling process in cold forming conditions. Arch Metall Mater 52:289-297

30. Hana H-N, Kim K-H (2003) A ductile fracture criterion in sheet metal forming process. J Mater Process Technol 142:1231-1238 